\title{
PRODUÇÃO E QUALIDADE FÍSICO-QUÍMICA DE FRUTOS DE LARANJEIRAS 'VALÊNCIA' EM DIFERENTES INTENSIDADES E FREQUENCIAS DE PODA ${ }^{1}$
}

\author{
EMILIANO SANTAROSA ${ }^{2}$, OTTO CARLOS KOLLER ${ }^{3}$, BRUNO CASAMALI ${ }^{4}$ \\ HENRIQUE BELMONTE PETRY ${ }^{5}$
}

RESUMO - A poda de frutificação em citricultura pode ser aplicada com o objetivo de controlar o crescimento vegetativo e promover a formação de novos ramos frutíferos. Neste sentido, o objetivo deste trabalho foi avaliar diferentes regimes de poda manual em pomares jovens de Laranjeiras 'Valência', cultivadas em manejo convencional. Utilizou-se um pomar com espaçamento de 5,0 x 2,5 m, implantado em 2001 no município de Montenegro-RS, Brasil. Os tratamentos, com início em 2004, foram: A - Testemunha (sem poda); B Poda anual de 15\%; C - Poda bienal de 15\%; D - Poda bienal de 30\%; e E - Poda trienal de 30\% do volume da copa. O delineamento experimental foi de blocos ao acaso, sendo quatro repetições e quatro plantas por parcela. Foram avaliados o número de frutos, massa total e massa média de frutos nas safras de 2006, 2007 e 2008. Foram avaliados aspectos relativos à qualidade dos frutos, como teor de sólidos solúveis totais (SST), acidez total titulável (ATT) e relação SST/AT. As podas de frutificação não alteraram significativamente a produção total de três safras, nem a qualidade físico-química dos frutos, em pomares de laranjeiras 'Valência' com menos de sete anos de idade, em sistema de manejo convencional.

Termos para indexação: Citrus sinensis, manejo, qualidade dos frutos.

\section{PRODUCTION AND PHYSICO-CHEMICAL QUALITY OF FRUITS IN 'VALENCIA' ORANGE TREES WITH DIFFERENT PRUNING INTENSITIES AND FREQUENCIES}

\begin{abstract}
The pruning in citrus can be applied with the objective to control vegetative growth and renew fruiting branches. This research aimed to evaluate different manual pruning regimes in young orchards of 'Valencia' Orange, grown in conventional management. It was used an orchard with spacing 5.0 x $2.5 \mathrm{~m}$, established in 2001 at Montenegro-RS, Brazil. The treatments, starting in 2004, were: A - control, without pruning; B - annual pruning of $15 \%$; C - biennial pruning of $15 \%$; D - biennial pruning of $30 \%$ and $\mathrm{E}$ - threeyear $30 \%$ pruning of the canopy volume. The experiment had a randomized complete-block design, with four-trees plots and four replications. It was evaluated the number of fruits, total fruit mass production and average weight fruit in the crops 2006, 2007 and 2008. Aspects relating to fruit quality, total soluble solids (TSS), total titratable acidity (TTA) and ratio (TSS/TTA) on juice were assessed. The manual pruning does not alter significantly the cumulative yield of three crops, nor physical-chemical and fruits quality in orchards of 'Valencia' orange under the age of seven, with conventional management system.
\end{abstract}

Index terms: Citrus sinensis, management, fruit quality.

\footnotetext{
${ }^{1}$ (Trabalho 035-13). Recebido em: 04-01-2013. Aceito para publciação em: 16-08-2013.

${ }^{2}$ Eng. Agr. Doutor em Fitotecnia / Fisiologia e Manejo Vegetal, EMBRAPA - Embrapa Florestas / CNPF. Estrada da Ribeira, km 111, Caixa Postal 319 - Colombo, PR - Brasil - 83411-000. E-mail: emiliano.santarosa@embrapa.br

${ }^{3}$ Eng. Agr., Doutor, Professor Aposentado do Departamento de Horticultura e Silvicultura e do Programa de Pós-graduação em Fitotecnia da UFRGS. Av. Bento Gonçalves, 7712, CEP: 91501-970, Porto Alegre - RS, Brasil.E-mail: ockoller@ufrgs.br

${ }^{4}$ Eng. Agr. MSc Student, University of Florida, Department of Horticultural Sciences. 1253 Fifield Hall, PO Box 110690, Gainesville FL 32611. Email: bruno.casa@terra.com.br

${ }^{5}$ Eng. Agr., doutorando do Programa de Pós-graduação em Fitotecnia da Universidade Federal do Rio Grande do Sul (UFRGS). E-mail: hbpetry@gmail.com
} 


\section{INTRODUÇÃO}

A citricultura no Brasil apresenta grande importância econômica e social, apresentando 777.642 ha de áreas colhidas em 2011 e totalizando 19.831.787 t de laranjas, com rendimento médio de $25.502 \mathrm{~kg} \mathrm{ha}^{-1}$ (IBGE, 2012). Entretanto diversas práticas de manejo ainda devem ser introduzidas com o objetivo de aumentar a produtividade, melhorar a qualidade dos frutos e reduzir custos de produção. Neste sentido, os sistemas de produção de Citros dependem do planejamento e de manejo adequado dos pomares para que ocorram melhorias na produção, sendo que a poda, em alguns casos, pode ser uma prática auxiliar dentro do sistema produtivo. Os principais sistemas de poda usados na citricultura são a poda de formação, a poda de frutificação, a poda de limpeza e a poda de rejuvenescimento (KOLLER, 2006).

A poda de frutificação em citricultura pode ser aplicada com o objetivo de controlar o crescimento vegetativo e de estimular a formação de novos ramos frutíferos, aumentando a luminosidade e o arejamento no interior da copa, e alguns casos apresentando influência sobre o tamanho, massa e qualidade dos frutos produzidos, dependendo das condições de cultivo. Estes fatores fazem da poda uma prática importante tanto para a produção quanto para a qualidade de frutos, principalmente em pomares de citros cujos frutos se destinam ao consumo in natura (SARTORI et al., 2007), sendo considerada uma ferramenta auxiliar para o manejo do pomar, facilitando também os tratos culturais, como tratamentos fitossanitários e a colheita. Entretanto, alguns trabalhos demonstram que a poda não interfere na qualidade dos frutos de tangerineiras (MEDEIROS et al., 2009), nem de laranjeiras com menos de sete anos de idade, conduzidas em sistemas orgânicos de produção (SANTAROSA et al., 2010).

Em determinados locais, a poda é aplicada de maneira mecanizada em pomares com alta densidade de plantas, em razão do excessivo desenvolvimento vegetativo da copa, que ao longo do tempo provoca a diminuição da insolação e a competição entre plantas na linha. Com isso, a produção em pomares com maior densidade de copa pode diminuir ao longo do tempo, devido ao excesso de sombreamento (YILDIRIM et al., 2010). Por isso, a poda mecânica em cítrus tem sido pesquisada em alguns locais para reduzir custos e aumentar o retorno econômico da cultura (VELAZQUEZ-MARTI; FERNANDEZGONZALEZ, 2010), bem como tem sido testada como ferramenta no controle fitossanitário (LOPES et al., 2007). Em alguns casos, a poda é utilizada para facilitar a maior luminosidade no interior da copa e favorecer a produção de frutos com maior qualidade (KOLLER, 2006). Mas também, torna-se necessário avaliar o efeito da poda manual em regiões que dificultam a utilização de mecanização e onde a poda é realizada, predominantemente, de forma manual.

Apesar de constituir-se como uma prática usual e importante para a cultura de citros em algumas regiões e em determinados sistemas de manejo, as plantas cítricas podem apresentar restrições quanto às podas severas e frequentes, podendo diminuir a produtividade nos anos subsequentes a essa operação. Diferentes intensidades e frequência de poda também podem exercer pouca influência sobre a produtividade e a qualidade dos frutos, dependendo do manejo, como em pomares jovens submetidos a sistemas orgânicos de produção (SANTAROSA et al., 2010).

O planejamento do regime de poda a ser aplicado depende de diversos fatores, como a combinação do porta-enxerto e a variedade da copa, vigor vegetativo e espaçamento de plantio. Também depende do manejo do pomar, incluindo adubação, irrigação e manejo do solo. Para facilitar o planejamento e a execução, a poda manual em citros pode ser considerada forte, quando são eliminados mais de 30\% da copa; normal, quando são retirados $20 \%$ dos ramos; e leve, com retirada de até $10 \%$ dos ramos (RODRIGUES PAGAZUARTUNDÚA; VILLALBA BUENDÍA, 1998).

A falta de estudos e a divergência nos resultados sobre poda em citros requerem testes em diferentes locais e condições de manejo, considerando também a aplicação da poda em regiões onde se concentra a Citricultura com mão de obra familiar e onde a prática da poda é aplicada de forma manual. A influência da poda sobre a qualidade dos frutos também necessita ser avaliada, podendo ser importante em frutos destinados ao consumo in natura. Considerando estes aspectos, o objetivo deste trabalho foi avaliar o efeito da frequência e da intensidade da poda manual sobre a produção e a qualidade físico-química de frutos em pomares jovens de laranjeiras 'Valência' [Citrussinensis (L.) Osbeck], submetidos ao manejo convencional.

\section{MATERIAL E MÉTODOS}

O experimento foi executado em pomar de laranjeira 'Valência' enxertada sobre Poncirus trifoliata (L.) Raf., implantado em agosto de 2001, com espaçamento de 5,5 m entre linhas e $2,5 \mathrm{~m}$ entre plantas, conduzido no sistema de manejo convencional. O pomar $\left(29^{\circ} 42^{\prime} 48.51^{\prime \prime S}\right.$ e 
$51^{\circ} 28^{\prime} 32.02^{\prime \prime}$ ) foi implantado na área experimental do Centro de Formação da Emater-RS, no município de Montenegro-RS, localizado no Vale do Rio Caí, na Depressão Central do Rio Grande do Sul. A topografia da região é levemente ondulada e com altitudes inferiores a $100 \mathrm{~m}$, onde o solo da área experimental é classificado como Argissolo Vermelho distrófico típico. A região apresenta clima subtropical úmido de verão quente do tipo Cfa. Os meses mais quentes apresentam temperatura média próxima de $25^{\circ} \mathrm{C}$, e os meses mais frios, temperatura média de $9^{\circ} \mathrm{C}$. A precipitação pluviométrica média anual é de $1.440 \mathrm{~mm}$, e a umidade relativa média do ar, de $77,3 \%$.

O delineamento experimental foi o de blocos ao acaso, com cinco tratamentos e quatro repetições, sendo utilizadas quatro plantas úteis, em linha, por parcela. A primeira poda de frutificação foi realizada em dezembro de 2004 e, nos anos subsequentes, sempre no mês de outubro, após a colheita dos frutos. Foram testadas diferentes frequências e intensidades de poda com base no volume de copa removida: A Testemunha (sem poda); B - Poda anual de $15 \%$ do volume da copa; $\mathrm{C}$ - Poda bienal de $15 \%$ do volume da copa; D - Poda bienal de 30\% do volume da copa; e E - Poda trienal de 30\% do volume da copa (Tabela 1).

A poda compreendeu o corte seletivo de ramos, cuja intensidade se baseou na percentagem podada do volume da copa, segundo metodologia de Rodrigues Pagazuartundúa e Villalba Buendía (1998). O volume da copa (V) foi obtido medindo-se o diâmetro das copas no sentido longitudinal (DL) e transversal (DT) às linhas das plantas e a altura da copa (h), em que: V = DL x DT x h. Durante a execução dos tratamentos, os ramos podados foram amontoados ao lado de cada planta a título de comparação e também para a medição do volume de ramos podados. Os ramos foram podados pela base, sendo eliminados os ramos mal posicionados, galhos verticais muito altos e os ramos frutíferos mais velhos. Na periferia da copa, efetuou-se a poda seletiva, podando ramos considerando um raio de $50 \mathrm{~cm}$ de distância um do outro ou um ramo a cada $0,125 \mathrm{~m}^{2}$ de copa, promovendo um raleio e estimulando a brotação de novos ramos produtivos, de tal modo que fosse promovida maior entrada de luz no interior da copa e obtenção de maior equilíbrio entre crescimento vegetativo e reprodutivo das plantas. Consequentemente, foram retirados alguns ramos com potencial produtivo, tanto na periferia quanto no interior da copa, a fim de verificar o efeito da intensidade e da frequência da poda sobre a produção e a qualidade físico-química dos frutos ao longo de três safras. As ferramentas utilizadas para a realização da poda foram tesoura de poda, para ramos com até $2 \mathrm{~cm}$ de diâmetro, e serrote manual, para ramos com mais de $2 \mathrm{~cm}$ de diâmetro.

Os tratos culturais do pomar consistiram em aplicações de herbicidas, produtos fitossanitários (fungicidas e inseticidas) e adubos minerais, conforme recomendações para cultura de Citros (ROLAS, 2004). Foram realizadas duas a três aplicações anuais de herbicida, ao longo das linhas e entrelinhas de laranjeiras. Foram realizadas adubações de acordo com as recomendações para cultura de Citros, incluindo adubação de plantio e adubação anual de cobertura, sendo a adubação mineral realizada anualmente nos meses de maio e agosto (KOLLER, 2006). O manejo fitossanitário foi realizado com aplicação de produtos registrados para cultura no período de maior brotação e suscetibilidade a doenças, principalmente durante o período de primavera-verão.

A colheita foi realizada em setembro, e as plantas foram avaliadas por meio da determinação do número e da massa total dos frutos produzidos por planta, nas safras de 2006, 2007 e 2008 (cinco anos de aplicação dos tratamentos). Também foram avaliados aspectos relativos à qualidade físico-química dos frutos, como massa média por fruto; teor de sólidos solúveis totais (SST); acidez total titulável (ATT) e índice de relação do teor de sólidos solúveis totais e acidez total titulável (SST/AT).

A acidez total titulável (ATT) foi avaliada por titulação com NaOH 0,085 N.O cálculo do teor de acidez foi realizado aplicando a seguinte fórmula: $\%$ ATT $=$ V x N x 0,064 x $100 / \mathrm{G}$, sendo: ATT= acidez total titulável em gramas de ácido cítrico; V $=$ volume de hidróxido de sódio gasto na titulação, em ml; $\mathrm{N}=$ Normalidade do $\mathrm{NaOH} ; 0,064$ = fator para expressar a acidez em ácido cítrico, em meq; $\mathrm{G}$ = massa da amostra (6g). O teor de SST foi obtido pingando duas a três gotas de suco, retiradas da amostra homogeneizada, em um refratômetro de bancada (modelo 2 WJ ABBE REFRATOMETER). A quantidade de SST foi expressa em ${ }^{\circ}$ Brix. A relação SST/ATT foi obtida a partir das determinações anteriormente realizadas para sólidos solúveis totais (SST) e para acidez total titulável (ATT).

As variáveis foram submetidas ao procedimento de modelos mistos do software de análise estatística SAS, e as médias entre tratamentos e entre anos foram comparadas pelo teste de Duncan, com nível de significância de 5\% de probabilidade. 


\section{RESULTADOS E DISCUSSÃO}

No quinto ano de idade das plantas e primeiro ano de avaliação (safra 2006), não houve diferenças entre os tratamentos de poda referente ao número de frutos produzidos (Tabela 2), provavelmente em virtude do menor desenvolvimento das plantas. A partir do $6^{\circ}$ ano de idade (safra 2007), verificam-se os tratamentos "B" (poda anual de 15\%), "C" (poda bianual de 15\%) e "D" (poda bianual de 30\%), que foram aplicados após a safra de 2006, e não provocaram diminuição no número de frutos por planta, quando comparados ao tratamento" $A$ " (Testemunha - sem poda). Porém, o tratamento com poda trienal de $30 \%$ apresentou maior número de frutos, em consequência da recuperação das plantas em termos de desenvolvimento de ramos produtivos, uma vez que, neste tratamento, a poda foi realizada apenas no primeiro ano de aplicação dos tratamentos, após a safra de 2004 (Tabela 2). O tratamento "E" (poda trienal de $30 \%$ ), que foi realizado pela segunda vez posteriormente à safra de 2007, apresentou o menor número de frutos na safra de 2008, afetando diretamente a produção da safra subsequente a sua aplicação. Neste caso, a poda severa de ramos produtivos refletiu- se diretamente na diminuição da produção de frutos no ano subsequente (safra 2008).

Também, observa-se um aumento significativo no número de frutos produzidos em todos os tratamentos na safra de 2008, inclusive da testemunha, comparando aos anos anteriores. A laranjeira, dependendo do sistema de cultivo, estabiliza sua produção com idade igual ou acima do limite superior das plantas avaliadas nesta pesquisa. Portanto, ocorre aumento da produtividade devido ao desenvolvimento anual da copa, sendo necessário avaliar continuamente o efeito da poda sobre a produção, também em plantas mais velhas, a longo prazo. Deve-se considerar que as plantas utilizadas nesta pesquisa apresentavam idade inferior a sete anos.

Os resultados sobre a massa total de frutos produzidos apresentaram um comportamento similar ao número de frutos (Tabela 3). A poda bienal de 15\% foi realizada pela segunda vez depois da safra de 2006, não afetando a produtividade na safra de 2007 (safra subsequente) em relação à testemunha. Sendo que, na safra de 2008, a planta apresentou maior massa total de frutos produzidos. Também verifica-se que a poda trienal de $30 \%$, executada posteriormente à safra de 2007, teve impacto significativo sobre a massa total de frutos produzidos na safra de 2008.

A execução da poda trienal de $30 \%$ caracteriza-se por ser uma poda severa, com grande retirada de ramos produtivos, reduzindo a produtividade no ano subsequente à sua aplicação, verificado a partir da safra de 2007 ou sexto ano de idade das plantas. Porém, os resultados também indicam uma recuperação da produtividade no segundo e terceiro anos após a poda de $30 \%$, verificando pouca interferência nos primeiros anos de avaliação. Ao mesmo tempo, verifica-se que a poda bienal de $30 \%$ também apresentou produções semelhantes à testemunha nas safras de 2006, 2007 e 2008.

O tratamento "B" (poda anual de 15\%) apresentou pouco impacto sobre o número e a massa total de frutos produzidos no ano subsequente a sua aplicação, quando comparado à Testemunha. A poda anual de $15 \%$ provoca menos impactos sobre a produção do ano subsequente por caracterizar-se como poda menos intensa (poda leve), com menos retirada de ramos produtivos, e apresenta influência anual sobre o controle de crescimento da planta e produção por ser aplicada com mais frequência. As podas de 15\% não reduziram a produção no ano subsequente, em relação à Testemunha, sendo que a poda bienal de $15 \%$ apresentou maior produção de frutos na safra de 2008 (na segunda safra após a poda) em relação à poda trienal de $30 \%$.

Entretanto, a poda anual de $15 \%$ e a bianual de $30 \%$ também não apresentaram diferença em relação à Testemunha nos anos subsequentes a sua aplicação (safras de 2006, 2007 e 2008), indicando a rápida recuperação da produção após a aplicação da poda também nestes tratamentos, em plantas jovens. A poda trienal de $30 \%$, na safra de 2008 , ano subsequente a sua aplicação, com o dobro de intensidade e metade do tempo de recuperação, foi inferior apenas à poda bienal de $15 \%$; entretanto, foi similar à Testemunha, a poda anual de $15 \%$ e à poda bianual de $30 \%$, indicando rápida recuperação. Nas safras de 2006 e 2007, também não houver diferenças das podas em relação à Testemunha, exceto para poda trienal de $30 \%$, que foi superior aos demais na safra de 2007, correspondendo à terceira safra após sua aplicação. Ao contrário do observado em experimentos realizados por Santarosa et al. (2010), em pomares submetidos ao manejo orgânico, onde se verificou uma redução da produção de frutos no ano subsequente à realização da poda, tanto com aplicação de poda leves de $15 \%$ quanto de podas severas de $30 \%$.

A recuperação da produção observada nesta pesquisa pode estar relacionada ao maior desenvolvimento das plantas proporcionado pelo sistema de manejo. Nos resultados, verificaram-se menores impactos da poda sobre a produção, igualando-se à Testemunha, exceto para poda trienal de $30 \%$, que afetou a safra de 2008, safra subsequente após sua 
segunda aplicação. A adubação mineral e a menor competição com a cobertura espontânea proporcionados pelo manejo podem ter favorecido a rebrota das plantas e a produção de frutos após a poda, em todos os tratamentos.

Em análise total de três safras, verifica-se que não ocorreram diferenças entre os tratamentos na produção total de frutos. Os resultados deste experimento são parcialmente similares aos encontrados por Joubert e Stassen (2000), mostrando que a produtividade aumentou no segundo e terceiro anos após a execução da poda, o que pode ser relacionado à recuperação das plantas e aos resultados da poda bienal de $15 \%$ na safra de 2008 e à poda trienal de $30 \%$ na safra de 2007 . Os resultados da produção total dos três anos também são similares aos encontrados por Kallsen (2005), que obteve produção anual de frutos similar às plantas que não receberam poda, ou seja, não houve redução significativa da produção.

Portanto, vale ressaltar que os tratamentos de poda seletiva, exceto a poda trienal de $30 \%$, no sistema de manejo convencional, não diminuem a produção de frutos de laranjeiras 'Valência'. Dessa maneira, a poda poderia ser utilizada com outros objetivos, como os citados por Sartori et al. (2007), para melhorar a luminosidade e a aeração da copa, controlar o excesso de crescimento vegetativo, melhorar a sanidade do pomar pela retirada de ramos secos e facilitar tratos culturais, como tratamentos fitossanitários e a colheita, sem afetar significativamente a produtividade. Entretanto, se a finalidade for aumentar a produção, a poda não deve ser recomendada em plantas jovens, devido aos custos de execução.

Observando os dados das safras de 2007 e 2008, verificam-se diferenças entre os tratamentos para a massa média por fruto (Tabela 4), sendo uma variável relacionada à qualidade do fruto. $\mathrm{Na}$ safra de 2007, o tratamento "E" apresentou a menor massa média por fruto, em consequência do maior número de frutos produzidos no mesmo ano (Tabela 2). $\mathrm{Na}$ safra de 2008, o tratamento "C" (poda bienal de 15\%) apresentou o maior número de frutos produzidos e, em consequência, os frutos foram de menor massa média, reduzindo seu valor comercial para consumo in natura. Alterações na massa média por fruto, e consequentemente no tamanho por fruto, podem ser relacionadas à qualidade física dos frutos, principalmente quando destinados ao consumo in natura. Entretanto, nos anos subsequentes à realização da poda, em plantas jovens de laranjeiras, não foram observados relações diretas da redução da produção e aumento da massa média por frutos, quando comparado com a testemunha. Nas condições avaliadas, estes dados divergem parcialmente de Mendonça et al. (2006) com tangerineiras 'Ponkan', que indicam que, ao diminuir a produção, a poda aumenta a massa média dos frutos em safras subsequentes aos anos de sua execução. Em determinados sistemas de produção, a poda estimula a formação de novos ramos e folhas, podendo estimular o aumento do tamanho dos frutos, que é um aspecto importante para a produção de frutos para o consumo in natura. Mas não foram observadas relações diretas nesta pesquisa com laranjeiras 'Valência', possivelmente devido à menor idade das plantas. Além disso, dependem da espécie de Citros, pois segundo Mendonça et al. (2006), as tangerineiras apresentam respostas de produção diferentes em relação à poda. Em análise anual, nos dois últimos anos de avaliação, ocorreram diferenças significativas quanto à massa média dos frutos. Porém, a massa por fruto, considerando a média dos três anos de avaliação, foi similar aos resultados encontrados por Kallsen (2005), em que a poda manual de laranjeiras 'Navelina' não proporcionou melhorias na categoria de frutos produzidos, comparado às plantas que não receberam poda.

Os resultados obtidos nas safras de 2007 e 2008 são contrários aos obtidos por Joubert e Stassen (2000), que indicam que a poda diminuiu a produtividade no ano subsequente à sua realização em laranjeiras 'Valência' e aumentou o tamanho dos frutos. Através da análise da Tabela 3, verifica-se que os tratamentos B, C e D não diferem da Testemunha em 2007, e também o tratamento $\mathrm{E}$ em relação à Testemunha na safra de 2008, sem provocar uma diminuição significativa na produção de frutos, nem aumento significativo no tamanho dos frutos em relação à Testemunha. Estes resultados, comparados à bibliografia, indicam que o sistema de produção, o manejo e a idade das plantas podem interferir nos resultados e resposta das plantas à poda, sendo que, em análise da safra subsequente à realização da poda, outros resultados também foram encontrados por Santarosa et al. (2010), aplicando os mesmos tratamentos em sistema orgânico de produção.

As plantas não apresentaram diferenças entre os tratamentos de poda quanto às propriedades químicas dos frutos, referente ao teor de sólidos solúveis totais (Tabela 5), acidez total titulável (Tabela 6) e relação SST/ATT (Tabela 7). Estes resultados são similares aos encontrados por Medeiros et al. (2009), em que os diferentes tipos de poda não prejudicaram a qualidade de frutos nas três safras subsequente às podas. O que ocorreu foram alterações na qualidade química dos frutos devido às variações entre os anos, independentemente do Tratamento de poda. Em alguns casos, às poda permite a entrada de maior lumi- 
nosidade no interior da copa e, através do raleio, pode favorecer a produção de frutos com maior equilíbrio, coloração e maior qualidade (KOLLER, 2006). A poda anual diminui a produção em tangerineiras 'Montenegrina', mas melhora a qualidade dos frutos e diminui a alternância de produção (SARTORI et al., 2007). Entretanto, as aplicações dos diferentes tratamentos de poda nesta pesquisa não alteraram a qualidade química dos frutos de laranjeiras 'Valência'. Possivelmente, as plantas jovens ainda não foram afetadas pelo sombreamento interno da copa e por competição entre plantas na linha, sem que ocorram efeitos diretos da poda manual de frutificação sobre a qualidade dos frutos e também sobre a produção. Em pomares jovens com menos de sete anos, a aplicação da poda de frutificação com a finalidade de melhorias na qualidade química dos frutos não é recomendada para esta espécie, pois onera os custos de produção sem promover alterações a curto prazo, inclusive sem alterar a produção acumulada de três safras.

TABELA 1 - Cronograma de execução dos tratamentos de poda em pomar jovem de laranjeiras (Citrus sinensis Osbeck) cv. Valência, a partir do terceiro ano idade das plantas. Centro de Treinamento da Emater-RS, Montenegro-RS. 2004-2008.

\begin{tabular}{lccccc}
\hline \multicolumn{1}{c}{ Tratamentos } & Dez & Out & Out & Out & Out \\
& 2004 & 2005 & 2006 & 2007 & 2008 \\
\hline A - Testemunha & - & - & - & - & - \\
B - Poda anual 15\% & $15 \%$ & $15 \%$ & $15 \%$ & $15 \%$ & $15 \%$ \\
C - Poda bienal 15\% & $15 \%$ & & $15 \%$ & & $15 \%$ \\
D - Poda bienal 30\% & $30 \%$ & & $30 \%$ & & $30 \%$ \\
E - Poda trienal 30\% & $30 \%$ & & & $30 \%$ & \\
\hline
\end{tabular}

TABELA 2 - Número de frutos produzidos por planta de laranjeira 'Valência' submetida a frequências e intensidades de poda, em pomar sob manejo convencional. (Montenegro-RS, 2006-2008).

\begin{tabular}{|c|c|c|c|c|c|c|c|}
\hline \multirow{2}{*}{ Tratamentos } & \multicolumn{7}{|c|}{ Número de frutos (frutos planta ${ }^{-1}$ ) } \\
\hline & 2006 & & 2007 & & 2008 & & Total \\
\hline A- Testemunha & 54,6 & $\mathrm{~B}^{\mathrm{ns}}$ & 49,6 & $\mathrm{Bb}$ & 341,3 & $\mathrm{Aab}$ & $445,5^{\text {ns }}$ \\
\hline B- Poda anual 15\% & 51,9 & B & 58,4 & $\mathrm{Bb}$ & 296,7 & $\mathrm{Aab}$ & 406,9 \\
\hline C- Poda bienal $15 \%$ & 65,8 & B & 58,0 & $\mathrm{Bb}$ & 381,6 & $\mathrm{Aa}$ & 505,3 \\
\hline D- Poda bienal 30\% & 63,3 & B & 67,1 & $\mathrm{Bb}$ & 307,6 & $\mathrm{Aab}$ & 438,0 \\
\hline E- Poda trienal $30 \%$ & 51,6 & $\mathrm{C}$ & 102,7 & $\mathrm{Ba}$ & 239,2 & $\mathrm{Ab}$ & 393,4 \\
\hline $\mathrm{CV} \%$ tratamento & & & 47,4 & & & & 7,9 \\
\hline $\mathrm{CV} \%$ ano & & & 13,9 & & & & \\
\hline
\end{tabular}

Médias seguidas por letras minúsculas iguais na coluna e por letras maiúsculas iguais na linha não diferem entre si, com nível de 5\% de probabilidade, pelo teste de Duncan. ${ }^{\text {ns }}$ Não significativo na coluna.

TABELA 3 - Massa média de frutos produzidos por planta de laranjeira 'Valência' submetida a frequências e intensidades de poda, em pomar sob manejo convencional. (Montenegro-RS, 2006-2008).

\begin{tabular}{lccccccc}
\hline \multicolumn{1}{c}{ Tratamentos } & \multicolumn{7}{c}{ Massa média de frutos $\left(\mathrm{kg}\right.$ planta $\left.{ }^{-1}\right)$} \\
& 2006 & & 2007 & 2008 & Total \\
\hline A- Testemunha & 12,5 & $\mathrm{~B}^{\text {ns }}$ & 13,8 & $\mathrm{Bb}$ & 55,9 & $\mathrm{Aab}$ & 82,2 ns \\
B- Poda anual 15\% & 10,5 & $\mathrm{~B}$ & 14,3 & $\mathrm{Bb}$ & 51,9 & $\mathrm{Aab}$ & 76,7 \\
C- Poda bienal 15\% & 12,5 & $\mathrm{~B}$ & 13,7 & $\mathrm{Bb}$ & 61,5 & $\mathrm{Aa}$ & 87,7 \\
D- Poda bienal 30\% & 13,1 & $\mathrm{~B}$ & 15,5 & $\mathrm{Bab}$ & 54,7 & $\mathrm{Aab}$ & 83,2 \\
E- Poda trienal 30\% & 10,8 & $\mathrm{C}$ & 21,3 & $\mathrm{Ba}$ & 42,3 & $\mathrm{Ab}$ & 74,4 \\
\hline CV \% tratamento & & & 38,5 & & & & 7,7 \\
CV \% ano & & & 11,4 & & & & \\
\hline
\end{tabular}

Médias seguidas por letras minúsculas iguais na coluna e por letras maiúsculas iguais na linha não diferem entre si, com nível de 5\% de probabilidade, pelo teste de Duncan. ${ }^{\text {ns }}$ Não significativo na coluna. 
TABELA 4 - Massa média por fruto de laranjeiras 'Valência' submetidas a frequências e intensidades de poda, em pomar sob manejo convencional. (Montenegro-RS, 2006-2008).

\begin{tabular}{|c|c|c|c|c|c|c|c|}
\hline \multirow{2}{*}{ Tratamentos } & \multicolumn{7}{|c|}{ Massa média por fruto $\left(\mathrm{g}\right.$ fruto $\left.^{-1}\right)$} \\
\hline & 2006 & & 2007 & & 2008 & & Média \\
\hline A- Testemunha & 224 & $B^{n s}$ & 283 & $\mathrm{Aa}$ & 165 & $\mathrm{Cbc}$ & $224^{\mathrm{ns}}$ \\
\hline B- Poda anual 15\% & 221 & A & 243 & $\mathrm{Aab}$ & 177 & Babc & 213 \\
\hline C- Poda bienal $15 \%$ & 194 & B & 244 & $\mathrm{Aab}$ & 163 & $\mathrm{Bc}$ & 200 \\
\hline D- Poda bienal $30 \%$ & 207 & $\mathrm{AB}$ & 240 & $\mathrm{Aab}$ & 180 & $\mathrm{Ba}$ & 209 \\
\hline E- Poda trienal $30 \%$ & 211 & A & 211 & $\mathrm{Ab}$ & 178 & $\mathrm{Bab}$ & 200 \\
\hline $\mathrm{CV} \%$ tratamento & & & 9,4 & & & & 4,2 \\
\hline $\mathrm{CV} \%$ ano & & & 6,1 & & & & \\
\hline
\end{tabular}

Médias seguidas por letras minúsculas iguais na coluna e por letras maiúsculas iguais na linha não diferem entre si, com nível de 5\% de probabilidade, pelo teste de Duncan. ${ }^{\text {ns }}$ Não significativo na coluna.

TABELA 5 - Teor de sólidos solúveis totais (SST) dos frutos de laranjeira 'Valência' submetidas a frequências e intensidades de poda, em pomar sob manejo convencional. (Montenegro-RS, 2006-2008).

\begin{tabular}{|c|c|c|c|c|c|c|c|}
\hline \multirow{2}{*}{ Tratamentos } & \multicolumn{7}{|c|}{ Sólidos solúveis totais - $\mathrm{SST}\left({ }^{\circ}\right.$ Brix $)$} \\
\hline & 2006 & & 2007 & & 2008 & & Média \\
\hline A - Testemunha (sem poda) & 9,1 & $\mathrm{~B}^{\mathrm{ns}}$ & 7,9 & $\mathrm{C}^{\mathrm{ns}}$ & 10,1 & $\mathrm{~A}^{\mathrm{ns}}$ & $9,0 \mathrm{~ns}$ \\
\hline B - Poda anual de $15 \%$ & 8,9 & $\mathrm{~B}$ & 7,8 & $\mathrm{C}$ & 9,9 & $\mathrm{~A}$ & 8,9 \\
\hline C - Poda bienal de $15 \%$ & 9,3 & A & 7,7 & $\mathrm{C}$ & 9,6 & A & 8,8 \\
\hline D - Poda bienal de $30 \%$ & 8,7 & $\mathrm{~B}$ & 8,1 & $\mathrm{C}$ & 9,7 & A & 8,8 \\
\hline E - Poda trienal de $30 \%$ & 8,6 & $\mathrm{~B}$ & 7,8 & $\mathrm{C}$ & 9,7 & A & 8,7 \\
\hline $\mathrm{CV} \%$ tratamento & & & 4,5 & & & & 1,1 \\
\hline $\mathrm{CV} \%$ ano & & & 2,2 & & & & \\
\hline
\end{tabular}

Médias seguidas por letras minúsculas iguais na coluna e por letras maiúsculas iguais na linha não diferem entre si, com nível de 5\% de probabilidade, pelo teste de Duncan. ${ }^{\text {ns }}$ Não significativo na coluna.

TABELA 6 - Acidez total titulável (ATT) dos frutos de laranjeira 'Valência' submetida a frequências e intensidades de poda, em pomar sob manejo convencional. (Montenegro-RS, 2006-2008).

\begin{tabular}{|c|c|c|c|c|c|c|c|c|}
\hline \multirow{2}{*}{ Tratamentos } & \multicolumn{8}{|c|}{ Acidez total titulável - ATT (g ácido cítrico) } \\
\hline & 2006 & & 2007 & & 2008 & & & Média \\
\hline A - Testemunha (sem poda) & 1,06 & $\mathrm{BC}$ ns & 1,12 & $\mathrm{AB}^{\mathrm{ns}}$ & 1,21 & A & . & $1,13^{\mathrm{ns}}$ \\
\hline B - Poda anual de $15 \%$ & 0,95 & B & 1,12 & A & 1,15 & A & & 1,07 \\
\hline C - Poda bienal de $15 \%$ & 1,06 & $\mathrm{AB}$ & 1,12 & $\mathrm{AB}$ & 1,14 & A & & 1,10 \\
\hline D - Poda bienal de $30 \%$ & 1,06 & A & 1,11 & A & 1,19 & A & & 1,12 \\
\hline E - Poda trienal de $30 \%$ & 1,05 & A & 1,13 & A & 1,17 & A & & 1,12 \\
\hline $\mathrm{CV} \%$ tratamento & & & 2,8 & & & & & 1,4 \\
\hline CV \% ano & & & 2,5 & & & & & \\
\hline
\end{tabular}

Médias seguidas por letras minúsculas iguais na coluna e por letras maiúsculas iguais na linha não diferem entre si, com nível de 5\% de probabilidade, pelo teste de Duncan. ${ }^{\text {ns }}$ Não significativo na coluna. 
TABELA 7 - Índice de relação do teor de sólidos solúveis totais e acidez total titulável (SST/ATT) dos frutos de laranjeira 'Valência' submetida a frequências e intensidades de poda, em pomar sob manejo convencional. (Montenegro-RS, 2006-2008).

\begin{tabular}{|c|c|c|c|c|c|c|c|}
\hline \multirow{2}{*}{ Tratamentos } & \multicolumn{7}{|c|}{ Índice de relação SST/ATT } \\
\hline & 2006 & & 2007 & & 2008 & & Média \\
\hline A - Testemunha (sem poda) & 8,68 & $A^{n s}$ & 7,0 & $\mathrm{~B}^{\mathrm{ns}}$ & 8,3 & $A^{n s}$ & $8,0^{\text {ns }}$ \\
\hline B - Poda anual de $15 \%$ & 9,41 & A & 7,0 & $\mathrm{~B}$ & 8,7 & A & 8,3 \\
\hline C - Poda bienal de $15 \%$ & 8,85 & A & 6,9 & $\mathrm{~B}$ & 8,4 & A & 8,0 \\
\hline D - Poda bienal de $30 \%$ & 8,27 & A & 7,3 & $\mathrm{~A}$ & 8,1 & A & 7,9 \\
\hline E - Poda trienal de $30 \%$ & 8,28 & A & 6,9 & A & 8,3 & A & 7,8 \\
\hline $\mathrm{CV} \%$ tratamento & & & 5,7 & & & & 2,0 \\
\hline $\mathrm{CV} \%$ ano & & & 4,5 & & & & \\
\hline
\end{tabular}

Médias seguidas por letras minúsculas iguais na coluna e por letras maiúsculas iguais na linha não diferem entre si, com nível de 5\% de probabilidade, pelo teste de Duncan. ${ }^{\text {ns }}$ Não significativo na coluna.

\section{CONCLUSÃO}

As podas de frutificação não alteram a produção acumulada de três safras, nem a qualidade físico-química dos frutos, em pomares de laranjeiras 'Valência' com menos de sete anos de idade, não sendo recomendada a aplicação da poda de frutificação com esta finalidade, em pomares jovens de laranjeiras.

\section{AGRADECIMENTOS}

Ao Conselho Nacional de Desenvolvimento Científico e Tecnológico $(\mathrm{CNPq})$, pelo auxílio à pesquisa e pela concessão de bolsas de Doutorado, Mestrado e de Iniciação Científica. Ao Centro de Formação da Emater-RS, localizado em MontenegroRS.

\section{REFERÊNCIAS}

IBGE - Instituto Brasileiro de Geografia e Estatística Produção agrícola: levantamento sistemático da produção agrícola, 2011. Disponível em: $<$ http:// www.ibge.org.br>. Acesso em: 14 out. 2012.

JOUBERT, F.J.; STASSEN, P.J.C. The effect of time of pruning on yield, fruit size and greening disease incidence of Valencia citrus trees. Neltropika, South Africa, v. 309, p. 28-31, 2000.

KALLSEN, C.E. Topping and manual pruning effects on the production of commercially valuable fruit in a midseason navel orange variety. Hort Technology, Stanford, v.15, p. 335-341, 2005.
KOLLER, O.C. (Org.). Citricultura: 1. Laranja: tecnologia de produção, pós-colheita, industrialização e comercialização. Porto Alegre: Cinco Continentes, 2006. 396p.

LOPES S.A.; FRARE, G.F.; YAMAMOTO, P.T.; AYRES, A.J.; BARBOSA, J.C. Ineffectiveness of pruning to control citrus huanglongbing caused by Candidatus Liberibacter americanus. European Journal of Plant Pathology, Wageningen, v. 119, p. 463-468, 2007.

MEDEIROS, L. F.; MENDONÇA, V.; ALMEIDA, A. L. C.; OLIVEIRA, L.A. A.; MEDEIROS PAULA, Y. C. Production and quality 'ponkan' tangerine tree after recovering pruning. Revista Caatinga, Mossoró, v. 22, p. 166-173, 2009.

MENDONÇA, V.; RAMOS, J.D.; RUFINI, J.C.M.; NETO, S.E.A; ROSSI, E.P. Qualidade de frutos da tangerineira 'Ponkan' após poda de recuperação. Revista Ciência e Agrotecnologia, Lavras, v.30, n.2, p.271-276, 2006.

RODRIGUES PAGAZUARTUNDÚA, J.J.; VILLALBA BUENDÍA, D. Generalitat Valenciana. Conselleria de Agricultura, Pesca y Alimentacion. Série Citricultura, Valência, n.2, 15p, 1998.

ROLAS- Rede Oficial de Laboratórios de Análise de Solo e de Tecido Vegetal. Manual de adubação e calagem para os estados do Rio Grande do Sul e Santa Catarina. 10.ed. Porto Alegre: Sociedade Brasileira de Ciência do Solo, 2004. 400p. 
SANTAROSA, E; KOLLER, O.C.; PETRY, H.B.; CASAMALI, B. Frequência e intensidade de poda em pomar jovem de laranjeiras 'Valência' sob manejo Orgânico. Ciência Rural, Santa Maria, v.40, n.10, out.2010.

SARTORI, I.A.; KOLLER, O.C.; THEISSEN, S.; SOUZA, P.V.D.; BENDER, R.J.; MARODIN, G.A.B. Efeito da poda, raleio de frutos e uso de fitorreguladores na produção de tangerineiras (Citrus deliciosa Tenore) cv. Montenegrina. Revista Brasileira de Fruticultura, Jaboticabal, v.29, n.1, p. 5-10, 2007.
VELAZQUEZ-MARTI, B.; FERNANDEZGONZALEZ, E.The influence of mechanical pruning in cost reduction, production of fruit, and biomass waste in citrus orchards. Applied Engineering in Agriculture, St. Joseph, v.26, p.531-540, 2010.

YILDIRIM, B.; YEŞILOĞLU, T.; INCESU, M; KAMILOĞLU, M.; ÖZGÜVEN, F.; TUZCU, O.; KAÇAR, Y.A. The effects of mechanical pruning on fruit yield and quality in 'Star Ruby' grapefruit. Journal of Food, Agriculture \& Environment, Helsinki, v.8, n.2, p.834-838, 2010. 